\title{
Validity and utility of the Swedish version of the Cultural Competence Assessment Instrument
}

J ane Holstein, Gunilla M. Liedberg, Annika Öhman and Anette Kjellberg

The self-archived postprint version of this journal article is available at Linköping University Institutional Repository (DiVA):

http:// urn.kb.se/ resolve?urn=urn:nbn:se:liu:diva-156137

N.B.: When citing this work, cite the original publication.

Holstein, J., Liedberg, G. M., Öhman, A., Kjellberg, A., (2019), Validity and utility of the Swedish version of the Cultural Competence Assessment Instrument, British J ournal of Occupational Therapy, 82(7), 422-432. https:// doi.org/ 10.1177/0308022619825813

Original publication available at:

https:// doi.org/ 10.1177/ 0308022619825813

Copyright: SAGE Publications (UK and US)

http:// www.uk.sagepub.com/home.nav 


\section{Title}

Validity and utility of the Swedish version of the Cultural Competence Assessment Instrument

\section{Short title}

Validity and utility of an instrument for measuring cultural competence

\section{Authors}

1. Jane Holstein, MScOT, Department of Social and Welfare Studies, Faculty of Medicine and Health Sciences Linköping University, Sweden

2. Gunilla M. Liedberg, associate professor, Department of Social and Welfare Studies, Faculty of Medicine and Health Sciences, Linköping University, Sweden

3. Annika Öhman, assistant professor, Department of Social and Welfare Studies, Faculty of Medicine and Health Sciences, Linköping University, Sweden

4. Anette Kjellberg, associate professor, Department of Social and Welfare Studies, Faculty of Medicine and Health Sciences, Linköping University, Sweden

\section{Corresponding author}

Jane Holstein

Department of Social and Welfare studies, Linköping University

SE-601 74 Norrköping

SWEDEN

jane.holstein@liu.se

Phone: +46 (0)11 363102

Mobile: +46 (0)700 896066

\section{Abstract}


Introduction: Global migration as well as migration to Sweden has increased during the last few decades. A self-rating instrument, which measures cultural competence, could support occupational therapists' professional knowledge when they encounter clients from different cultural backgrounds. The purpose of this study was to evaluate the content validity and utility of the Swedish version of the Cultural Competence Assessment Instrument (CCAI-S) among occupational therapists. Nineteen occupational therapists participated in four focus groups.

Method: Qualitative analysis was used to evaluate content validity and utility.

Results: The results revealed that all 24 were valid, even though six of the items were in need of reformulations and exemplifications. The category Interactions with clients showed that the CCAI-S could be utilized individually to raise awareness on cultural issues in practice. The category Workplace and its organisational support showed that the CCAI-S had potential for use in different workplaces, and indicated the importance of organisational support in the development of communications and cultural competence.

Conclusion: The evaluation indicated positive content validity for the CCAI-S, and that it had the potential to be utilised in the Swedish context.

\section{Keywords:}

Instrument development, occupational therapy, qualitative research, ethnicity, cultural competence

\section{Background}

Globally, in 2015, approximately 244 million people lived in a country other than the one in which they were born, a figure almost 100 million greater than in 1990. This is more than three times more than was estimated in 1970 (IOM, 2017) . There has been a substantial increase in the number of foreign-born residents in Sweden during the last decades. In 2016, Sweden had approximately 9.9 million inhabitants and 1.6 million of them were foreign-born, i.e. one in six (SCB, 2016a). Since 1970, 2.7 million people have moved to Sweden. The 
reasons for migration have varied over the years, but have usually involved war and conflict, economic cycles or relationships (SCB, 2016b). Compared to Swedish-born persons, nonEuropean migrants in Sweden state three to four times more often that they have poor or very poor health. Specific public health problems, such as allergic diseases and diabetes, differs broadly through diverse immigrant groups. The background of refugees with experiences in wars before fleeing their countries makes them particularly vulnerable to psychiatric ill health and is exacerbated by the anxieties that follow during the asylum process (Hjern, 2012). Occupational therapists and other health professionals need to adapt and meet the changing demands and demographic characteristics of the general population (Pooremamali, Persson, \& Eklund, 2011). In addition, a model also point out that occupational therapists in practice need to be open minded to the unique cultural needs of a client (Darawsheh, Chard, \& Eklund, 2015). Given the challenges that practitioners may face in addressing the needs of ethnically and racially diverse populations' practitioners may find it useful to have access to tools that enable them to examine their perceived level of cultural competence(Taylor-Ritzler et al., 2010).

\section{Theoretical base for the CCAI}

Balcazar et al. (2009) conducted a systematic literature review to identify the most frequently used assessments of cultural competency and the theoretical models on which they were based. In addition, the review identified the guiding of training of cultural competence for practitioners. The findings revealed that most existing models of cultural competence include cognitive and behavioural elements, yet only a few highlight contextual components and organisational support in acquiring this competence. The literature review led to the development of a cultural competence model in 2009 and a revised model was introduced in 2011. The model consist of three domains. The cognitive domain reflects critical awareness and understanding, and consists of a complex process of self-reflection. It starts with the willingness to question his or her own beliefs, to change and learn from the client's culture. The behavioural domain concerns developing skills and abilities. This includes the development of the capacity of the professional to communicate effectively and empathetically with the person, as well as to incorporate the beliefs, values, experiences and ambitions of the specific person throughout the work process. The contextual domain emphasises organisational support for multicultural practices. The degree of organisational support for participation in cultural competence work is crucial, as a versatile staff increases 
the credibility and visibility of the various ethnic groups in society. Along with the model there is a corresponding self-rating instrument developed in United States, known as the Cultural Competence Assessment Instrument (CCAI) (Suarez-Balcazar et al, 2009).

\section{Description of the CCAI and CCAI-S}

The CCAI includes three sections. The first involves a number of demographic questions on gender, education, current work setting and occupation, years of practice and the ethnicity of the professional. This section comprises seven questions altogether. The next section involves questions on experience and perceived level of cultural competence, requesting information such as languages spoken by clients, continents of origin of the clients, opportunities for undergoing training or courses in cultural competence (nine questions). The last section of the instrument involves 24 self-rating questions designed to measure three factors: 1) Cultural awareness and knowledge, with eight items, 2) Cultural skills, with eight items, and 3) Organisational support for multicultural practice, with eight items. A six-point Likert-style scale was used, where 6 was "strongly agree” and 1 "strongly disagree” (Suarez-Balcazar et al, 2009). .

The CCAI is intended to provide the clinician and the organisation with an assessment tool to identify areas in need of training or supports (Suarez-Balcazar et al , 2011). The results of the instrument provide clinicians with an overall picture of aspects to consider in a cultural encounter. Once the instrument is completed, therapists might reflect about each item on the survey, set goals to improve their level of competence, and engage in dialogue with their supervisor or other clinicians on how to be sensitive to clients from ethnically and racially diverse backgrounds (Rodakowsk and Suarez-Balcazar, 2017). Clinicians may "find themselves adjusting their therapeutic strategies, trying different verbal and nonverbal communication strategies...” (Suarez-Balcazar, Rodakowsk, Balcazar, Taylor-Ritzler, Portillo, Barwacz and Willis, 2009, p. 503). The clinician can calculate on the own the level of competence and identify areas to work on. Researchers recommend that clinicians set at least two goals to work on based on the results of the instrument (Rodakowsk \& SuarezBalcazar, 2017; Taylor-Ritzler, Balcazar, Suarez-Balcazar, Dimpfl, Willis and Schiff, 2008). Based on survey results, work settings may realise that they need to embrace diversity and cultural relevance in their mission and vision statements, allocate resources for ongoing 
training and supports, foster a learning culture within the organisation, allow practitioners to adopt culturally relevant models of practice, and allow physical changes to their work space (e.g. adding posters and printed materials that depict ethnically and racially diverse populations), among other changes (Suarez-Balcazar et al., 2011).

The steps formulated by Beaton et al. (2000) guided the translation and adaptation process of the CCAI into the Swedish context (CCAI-S). The goal of the translation was to achieve equivalence between the original American version and the translated version. Three of the authors, (JH, GML, AK) worked on the translation process into Swedish by analysing all the questions, as well as each item of the instrument. All authors were native Swedish speakers. Each of the three authors translated items individually, and then reached consensus in terms of wording and adaptations through a number of meetings held in the form of a discussion. One cultural adjustment involved changing race to ethnicity. In Sweden, the concept of ethnicity is used in official documents such as the Discrimination Act (2015) as well as in everyday speech. In addition, cultural adaptations were made involving societal structure of the healthcare and educational systems. A bilingual, native-English translator then translated the instrument back into English. The translator had no prior knowledge of the instrument. The authors then compared the back-translated version to the original, and a few adjustments were made in terms of specific wording. The revised back-translated version was then sent to the original author of the instrument, who approved it. The instrument was pilot-tested in an initial focus group, which resulted in linguistic corrections in the demographic section. This first focus group was included in the study.

The original version of the CCAI has been validated among a randomized sample of 477 occupational therapists in United States. The psychometric analyses used in the study were explanatory and confirmatory factor analysis. The results demonstrated strong psychometric data for a three-factor model. The first factor was “Awareness/sensitivity to biases”, factor two was "Organizational support for multicultural practice" and factor three was "Skills". Each factor included eight items. The three factors showed fairly strong reliability ( SuarezBalcazar et al, 2011) 
To assess the content validity of the Swedish instrument in the current study qualitative methods was used. Content validity can be described as the extent to which the selected questions cover conceptual definitions within the scope of an area, and reflects the extent to which the measure adequately covers the domains (Polit and Beck, 2016). It is common to measure content validity by considering experts' critical opinions regarding for instance linguistic clarity and phrasing of the questions or items in an instrument, and this can be done through focus groups or interviews (McDowell, 2006). In addition, the current study assessed utility, which involves the potential of an assessment for application in a practical setting (Polit and Beck, 2004, 2008). One aspect of utility involves the clinical relevance of the assessment, or the potential for supporting decision-making in for example the treatment planning and enhancing communication in clinical practice. A second aspect of utility involves the instrument's potential for implementation, and includes the concepts of transferability and feasibility. Transferability comprises the administrative structure and the time needed to implement the assessment. Feasibility involves the availability of resources for implementing the assessment within the organisation, such as administrative support (Polit and Beck, 2004; 2008).

With the increasing diversity of Swedish society, healthcare professionals, like occupational therapists, are faced with challenges in terms of providing culturally relevant services, which maintain client centeredness during interaction. Therefore, there is a need to develop and measure cultural competence, and psychometrically tested instruments may provide a way of doing this. There is a lack of instruments for measuring cultural competence in Swedish, which are adapted to the Swedish context. Accordingly, the purpose of this study was to evaluate the content validity and utility of the Swedish version of the Cultural Competence Assessment Instrument (CCAI-S) among occupational therapists.

\section{Method}

\section{Research design}

This study used a descriptive, exploratory approach with focus groups. The use of qualitative research, specifically focus groups, for instrument development is a common method (Morgan, 1998) and is used for instance in testing content validity in QOL questionnaires 
(Connell et al, 2018; Liedberg et al, 2012), and when employing the Child and Adolescent Symptom Inventory (Bearss et al, 2016). A focus group is an interview in a small group setting, where individuals who share common characteristics in focused discussions contribute qualitative data on a specific topic of interest (Krueger and Casey, 2015). In this study, the purpose was to establish content validity. In this case, therapists who had had interactions with international clients represented the expert opinion. Morgan (1998) describes the advantages of focus groups for examining complex issues. In our study we considered cultural competence to be complex since this issue is a comparatively new one for occupational therapists in Sweden to reflect upon and discuss. In addition, the number of foreign-born residents in Sweden has increased during the last decades (Hjern, 2012) and cultural competence can therefore be regarded as a relatively new phenomenon to discuss. Consequently we preferred focus groups instead of individual interviews.

\section{Ethical considerations}

The study was conducted in accordance with Swedish law (SFS 2003:460) and ethical guidelines for research according to the Declaration of Helsinki (2013). The ethical principles governing confidentiality, the voluntary nature of the study and the requirement for informed consent were included in the study. All participants provided written and oral informed consent to participate in a focus group including the withdrawal process, and to have their anonymised data used in the study (Declaration of Helsinki, 2013). Ethical approval for the study from an official research ethics committee was not required since the purpose of the study posed no physical or psychological risk for the participants and no data regarding the participants’ private conditions was collected (SFS 2003:460).

\section{Participants}

Purposeful sampling (Patton, 2015) was used to reach occupational therapists working with children, adults of working age and the elderly. Gatekeepers (Aspers, 2011) from various work areas, such as inpatient and outpatient wards and the private sector, in the south part of Sweden, were contacted by e-mail and telephone. They were asked to forward an information letter to potential informants, along with a consent form based on the Declaration of Helsinki (2013). The inclusion criteria were as follows: 1) occupational therapists working with children, adults of working age or the elderly, and 2) during the past year they had to have had 
contact with international clients. The occupational therapists were considered as the experts due to their experiences in meeting international clients. The information letter gave a number of dates when focus groups would take place. A number of reminders were sent, and the period for the potential participants to respond was extended several times to provide greater opportunity to participate in a focus group. Interested participants were asked to give their consent and indicate when they could attend the focus group.

\section{Procedure}

Participants received the CCAI-S by e-mail, before attending the focus group, and were asked to fill it in and bring it to the focus group.

\section{Focus group}

The first author was the moderator of the focus groups and one of the co-authors was the comoderator. The emphasis for the moderator was on creating a welcoming environment which encouraged participants to share their understanding and experiences (Krueger and Casey, 2015) of working with international clients and to express their views of the CCAI-S instrument. Dahlin-Ivanoff et al. (2006) underline interaction as the basis for a focus group. At the end of the focus group, the first author collected all the completed instruments. The completed instruments were used to compile demographic data on the participants as well as their written comments on each item. To record who said what in the focus group, a video camera was used with the consent of the participants. A dictaphone was used to record the focus groups, and each focus group took approximately 1.5 hours. All four focus groups were conducted in university facilities. The first author transcribed all the interviews from the focus groups verbatim.

\section{Focus group interview guide}

To establish a structure for focus group discussions a guide was developed by the authors. The theoretical foundation for the interview guide was based on the establishment of content validity (McDowell, 2006) and utility (Polit and Beck, 2004; 2008). The guide included an initial open-ended question to start up the discussion about the meaning of culture and ethnicity. The question asked what opinion the participants had of the concepts and their first thoughts about it. The next six questions concerned demographics for the occupational 
therapist, such as education level, work area and ethnic background. The subsequent three questions concerned in what ways the occupational therapists had developed their knowledge regarding cultural competence, such as: "How have you obtained knowledge about cultural competence regarding ethnicity?” The next four questions aimed to capture the clinical experiences during the past year that participants had of encountering international clients. After that, the three factors 1) Cultural awareness and knowledge, 2) Cultural skills, and 3) Organisational support for multicultural practice, each with eight corresponding items in the CCAI-S were presented, with the accompanying question: "What meaning, linguistic clarity, relevance and representativeness does the item have for you?” When all the items was passed through the participants were asked to consider whether they had missed any items that were of importance for the concept of cultural competence. The participants were also asked for comments on the six-point Likert scale used. Finally, utility questions regarding the CCAI-S were asked, for example asking if there were general comments on the utility and if there were any examples of when and where to use the instrument in practice.

\section{Data analysis}

Descriptive statistics were used to describe demographic characteristics of the occupational therapists. The data concerning content validity was visually inspected and compared regarding similarities and differences reported by the participants concerning each factor and item in the CCAI-S (Polit and Beck, 2016). Qualitative data regarding utility were analysed by using content analysis (Graneheim and Lundman, 2004).

\section{Analysis of content validity}

The transcribed data regarding culture and ethnicity, the opening question, was used to summarise the participants' general understanding on these concepts, and emphasis was placed on the meaning which reflected the opinion of the whole group (Sim, 1998). Content validity was analysed in relation to each item in the transcribed data, together with the instruments the participants were asked to fill in before attending the focus groups. All the authors, in parallel, conducted their own analysis, and this was followed by a critical dialogue among all authors until consensus regarding the results was reached (Polit and Beck, 2016). This was made through 1) comparing similarities and differences between the focus groups' 
comments on each item, 2) comparing similarities and differences between comments in the completed instruments, and finally 3) a comparison of similarities and differences between focus groups and completed instruments. The qualitative analysis emphasised the level of understanding, considering for example linguistic clarity, relevance, representativeness, deviations from the concept of cultural competence, and if there was a need for additional items. If two out of four focus groups gave the same comment on an item, then the recommendation was adopted.

\section{Analysis of utility}

Qualitative content analysis based on the steps described by Graneheim et al. (2004) was used to analyse data. The transcripts from the focus group data were read through a number of times by the first author to obtain an overall understanding of the material. The first author extracted text concerning the utility of the instrument for analysis, with a focus on clinical relevance, for instance support in treatment planning,and potential for implementation. These text extracts were then read and analysed line by line by the first author. Meaning units were identified in the text, i.e. sentences which contained information relevant to the purpose of the study. These units were then condensed, i.e. shortened with the essence of the content preserved. Meaning units were coded and grouped into categories. The encoding process for obtaining homogeneous categories was iterative, and was supported by discussions with all authors on similarities and differences between the categories. After the data had been fully categorised, the transcripts were re-read by the first author, together with the categories, in order to verify the findings. To make the categorisation more trustworthy, discussions took place between all authors until consensus was reached (Breitmayer, Ayres, and Knafl, 1993). The analysis resulted in two categories. Quotes from the focus groups are presented in the results to verify the results, using the abbreviation FG1 for the first focus group, etc.

In qualitative research the concepts credibility, dependability and transferability have been used to describe various aspects of trustworthiness (Graneheim and Lundman, 2004; Krefting, 1991). The dependability of the study was increased by presenting an accurate description of the procedure and the process of analysing data in the study (Krefting, 1991). A rich presentation of the findings together with appropriate quotations enhanced transferability of 
the study (Graneheim and Lundman, 2004). Furthermore, transferability was ensured in the selection and characteristics of participants, data collection and process of analysis. Choosing participants with various experiences increases the richness of data addressing research questions, thus enhancing credibility (Graneheim and Lundman, 2004).

\section{Results}

\section{Characteristics of the participants}

Twenty-four occupational therapists gave their consent via email to participate in a focus group. However, five of them were unable to attend. A total of 19 occupational therapists participated in one of four focus groups composed of four to five people each, held between August 2015 and May 2016. The characteristics of the participants are presented in Table 1. They varied in age from 27-55 years. Most of the participants had a bachelor's degree. Eight participants had up to five years of experience, four had 6-15 years and six had 16-30 years. The majority of the participants identified their ethnic background as Swedish.

Insert Table 1 here

\section{Content Validity of the CCAI-S}

In connection with the opening question all focus group participants discussed culture in terms of context, community and groups in which people live their lives. Participants expressed views that there are different norms, beliefs, agreements and values in diverse cultures, which are transmitted from generation to generation. All focus groups described ethnicity as the background and the origin or country from which a person comes. Individuals can have the same ethnic background but different cultures.

Comments from the participants were in agreement concerning the 24 items included in the instrument. They regarded them as relevant and representative for cultural competence. 
Furthermore, no items were suggested to be removed or added. The specific comments on the items in the instrument resulted in suggestions for alterations from the participants in terms of improving the clarity of six items, for example by reformulations and use of examples (Table 2). The six items were equally distributed by two items in each factor. The six-point Likert scale was considered relevant by the participants.

Insert Table 2 here

Further comments for improving content validity of the instrument were provided by the participants. They reported a need for instructions on how to fill in the instrument and for a definition of cultural competence in the introduction. Suggestions were made about changing the demographic section to include only continents, since the participants reported problems in deciding which countries clients originated from.

\section{Utility of the CCAI-S}

The focus group participants described how the CCAI-S could be utilised individually to raise awareness about weaknesses and strengths in practical situations with foreign born clients. The participants also acknowledged that the CCAI-S could be utilised in the workplace and that organisations could support the development of cultural competence among practitioners.

\section{Interactions with clients}

All focus groups noted that the CCAI-S was clinically relevant at a personal level, since it stimulated reflection about previous personal experiences with clients from different cultural and ethnic backgrounds. Most participants reported that the CCAI-S helped them reflect on ethnicity, difficulties and strengths in professional practice, and on areas requiring improvement. "I think it is quite a good instrument for making me think about ethnicity and discovering where my difficulties or my strengths are” (FG1). 
In discussing the items on communication, all focus groups suggested the CCAI-S could be utilised and could give support to the therapist during the occupational therapy process, and the participants discussed the importance of adapting to cultural meetings. Most participants described feelings of uncertainty and confusion in exploring difficulties in verbal communication with international clients who did not have Swedish as their first or second language. Most participants addressed the communication problems by simplifying the verbal language or using alternative methods such as sign language, visuals and body language. This was exemplified by one group as follows: “So, a lot of it's to do with body language. It's how much you show what you mean if you demonstrate with your body. So you become non-verbal, but the question is whether it's understandable" (FG1).

Most of the participants recognised that one item in the CCAI-S raised awareness of the importance of considering clients' cultural celebrations in professional decision-making. “ $I$ consider it important. I do not go to visit this person in their home, for example, at Chinese New Year; we meet the following week instead" (FG1). Most participants considered that decision-making was facilitated by adapting to the client's culture, although a few participants had some concerns about how reasonable it was. "It is important in encounters with clients that there is an understanding that I do not change from what I set out to do, or from my goal. From this starting point, maybe I can adapt, and then I think of different ways of approaching the person" (FG2).

In discussing the item: "I do not consider the cultural backgrounds of my clients where food is concerned”, almost all participants described familiar situations involving food, including a number of types of assessment and intervention. Difficulties in making relevant assessments and appropriate adjustments to the clients' culture in this specific situation were expressed in one group as follows: "We assessed a client in baking a sponge cake, something that most people are familiar with, know the ingredients for and know how to do. However, this client's cultural background meant that she had never baked this cake. So we had to adapt to the situation and bake a type of bread she usually baked, so that we could make a reasonable assessment and she could complete it successfully" (FG2). In this situation, the need for adaptations and adjustments was clear, as baking a sponge cake did not make any sense to the client. 


\section{The workplace and its organisational support}

All focus group participants underlined the potential for implementation of the CCAI-S in different workplaces, since it could capture the need for support from the organisation in the area of cultural competence. All the participants considered that the CCAI-S could be utilised in their own workplace, and gave examples of other types of workplace where it could be utilised, such as employment offices, social security offices and schools. Other areas suggested included educational occupational therapy programmes and in teams with diverse professions, or in OT-only teams. "I think it could be a good help for a team in these areas, partly to map the area but also to raise questions for discussion” (FG1). An approach for implementing and using the CCAI-S in a workplace was suggested by most focus groups. First, the current situation in terms of cultural competence would need to be measured and summarised. Specific activities would then need to be introduced to improve cultural competence, such as reflection, logbooks, lectures and discussions, and finally a follow-up measurement and comparison would have to be made with the first measurement to assess improvement. "You can also use it initially to get an overview. Then you work actively in a workplace, and then you measure again to see if there is any difference” (FG1).

In discussing the item: "My organisation does not provide ongoing training on cultural competence”, all participants noted that they had become more aware of whether or not they received cultural support from their organization. "If I acquire cultural competence [education] through my organisation, maybe I'll act better in meetings with my client, but that's a step the organisation has to take” (FG4). The knowledge participants had acquired so far regarding other cultures was not based on formal education from the organisation. It had been acquired informally through direct experience and practical learning in cultural encounters with people from other countries. "I have learned this through practical experience and in meetings with many people I have met. But at the same time I have no formal knowledge of cultural competence" (FG4). All participants noted that the CCAI-S clarified the importance of engaging managers to recognize the need for cultural competence among the staff. "I believe in the idea of this topic, and if the boss says you have to do it, you have to. If you can explain the purpose, it feels like my colleagues are very positive about how to improve" (FG3). The experience shared by most of the participants involved managers who 
did not prioritise cultural competence. "The boss does not prioritise such things [cultural competence]" (FG2). Some participants described ways that CCAI-S stimulate thoughts about the workplace from a cultural competence perspective and about the advantages of increased knowledge: "Yes, it's because it raises questions about the workplace, about promoting cultural skills and ongoing education. You can ask the manager for the opportunity to attend a conference or a lecture on cultural competence and explain the benefits for the patient if you do" (FG1).

In discussing the item: “Cultural competence is included in my workplace’s mission statement, policies and procedures”, all participants stated that the CCAI-S made them realise there was no specific policy goal related to cultural competence in their organisation, just general objectives based on the Discrimination Act. "I don't think there are any goals. Of course there are certain guidelines about everyone being treated equally, but no goals" (FG3). In contrast, one workplace had drawn up a plan to formulate concrete policy goals on the topic when management recognised the need.

In connection with several items on opportunities to learn and obtain feedback from colleagues on cultural skills, the participants felt this was a way of feeling supported by the organisation. All participants had varying experience of this type of support. In some workplaces, participants perceived uncertainty and fear among staff in terms of giving feedback to each other on the level of competence. "I think it may be quite difficult for my colleagues to handle because I have a different background and no one else has. I have never received feedback from a colleague” (FG3). In other workplaces, participants perceived a more open climate, with cultural diversity within the staff, which provides support for learning. “We have considerable diversity in our company. You can get a great deal of support from them in terms of your own behaviour - how to act and how not to act. So I think you can get it if you ask for it" (FG3).

Resources for communication in the organisation, such as interpreters, can indicate whether or not support is available. Several items in the CCAI-S involve the use of professional interpreters, and all participants described this as generally problematic. "It's easier if you do 
not have to work with an interpreter, because it always interrupts communication” (FG 2). They gave examples where interpreters could not be understood because the language or dialect were wrong for the patient. Some participants described help from other healthcare professionals with the same ethnic background, or mentioned patients or a relative interpreting, but this was perceived by these participants as a hindrance to communication.

One item highlighted the area of available resources in the workplace, such as pictures and printed materials, and whether they reflected the clients' culture. All focus groups stated that this was generally lacking. Written information in relevant language on exercises and assistive equipment was described by all focus groups as frequently incomplete, although some had brief translations in a couple of languages. If the information was available, it rarely reflected the patients' culture. "I think more about what obligations we have, and information about assistive equipment is available in many languages if you print it out. However, in our workplace we have not organised a translation of our material” (FG4). Some participants may even feel hindered by this in the work setting to the extent that they make their own attempts to translate materials using a variety of Internet tools. "I had to try to translate into Arabic by myself, but it's hard. You sit there and try Google translate, and try to do it. However, it isn't easy. It will give you the wrong meaning sometimes” (FG3).

In connection with the item: "My workplace does not support my participation in my clients' cultural celebrations", some participants felt that the organisation provided support by giving the opportunity to adjusting their timetable to clients' festivities in terms of conducting home visits.

\section{Discussion}

The emphasis of the current study was on instrument development in terms of evaluating the content validity (Polit and Beck, 2016) and utility (Polit and Beck, 2004; 2008) of the CCAIS among Swedish occupational therapists. Overall the participants reported no added or removed factors or items. The result indicated positive content validity for the CCAI-S, where 18 out of 24 items were considered valid. Six items were evaluated as in need of minor clarification and exemplification. The suggestions for adjustments given by the participants 
on the six items need to be considered in further developing the CCAI-S. Further, the participants described that they lacked guidelines on how to fill in the instrument and they also pointed out the need for a definition of the concept “cultural competence”. These suggestions are particularly important and enhance the validity of the CCAI-S. This will be included in the Swedish version of the CCAI.

The CCAI-S was shown to be clinically relevant in a number of ways. It could be used at a personal level, as it stimulated reflection on previous experience with clients from different cultural backgrounds, and assisted reflection on difficulties and strengths in professional practice towards improvement in the area. Participants described a learning process where the CCAI-S could help develop cultural competence in staff. Balcazar et al (2009) describe this like a lifelong process for improving cultural competence and acquiring up-to-date knowledge in health and care systems. In the current study, most participants also described feelings of uncertainty and confusion when they explored difficulties in verbal communication with international clients who did not speak Swedish. This was also found in a study by Pooremamali et al. (2011) describing Swedish occupational therapists working in psychiatric settings who were attempting to improve their cultural competence to help cope with uncertainty, misunderstandings and confusion in meetings with international clients.

In terms of clinical relevance, the CCAI-S showed the importance of communications skills in challenging interactions with clients and in further assisting in decision-making during the treatment planning process. The participants exemplified how they adapted to meetings with people from different cultures by simplifying verbal language or using alternative methods such as sign language, or visual and body language. Pooremamali et al. (2011) described misunderstandings resulting from barriers in verbal and non-verbal communication and in the use of translators. The result in the present study revealed that the resources available in an organisation are important in terms of developing cultural competence in occupational therapists, including engaged managers and goals related specifically to cultural competence. However, as support in organisations was described as insufficient in a number of ways, the potential for implementing the CCAI-S may be limited. Balcazar et al.(2009) suggested that modifications are required in an organisation, such as guidelines and policies, to enable practitioners to apply cultural competence in their workplace. In addition, no matter how 
experienced and critically aware occupational therapists are in terms of multicultural issues, and no matter how prepared they are to adapt to their international clients, they may be hindered by inflexible guidelines in the organisation. The participants in the current study had learned cultural competence informally, not through support from the organisation. This is in accordance with Pooremamali et al. (2011) where occupational therapists largely acquired cultural competence informally, and through applied teaching and relevant communication methodology.

In terms of clinical relevance, based on items in CCAI-S the participants noted that there was a general lack of written information in relevant language, which led them to attempt their own translations or remain entirely without relevant information. This suggests a need for organisations to increase their resources in terms of providing information materials, which mirror the demographics of their clients. Wray and Mortenson (2011) emphasise that strategies for engaging with clients from diverse populations could involve the use of interpreters or translated written materials. It could also involve exhibiting materials representing a variety of cultures in the physical environment, and taking part in groups to stimulate cultural learning in the workplace. Obviously, conducting the Swedish version of CCAI led to reflections in the focus groups on issues such as how the workplace and organisational context supported the practitioners with providing written materials in different languages. This gives support to the relevance of the items focusing on the factor organisational support for multicultural practice and highlights the implementation potential of the CCAI-S in a Swedish context.

Almost all of the participants reported problems with using professional interpreters, which can be viewed as resources in the organisation, in their daily practice. Organisations need to support the use of interpreters (Balcazar et al., 2009), who should be appropriate in terms of gender and minority languages, even though these interpreters may not be readily available (Hultsjö, 2005). One solution to language problems described by participants in the current study involved other healthcare professionals or relatives acting as interpreters, but this was regarded with a level of uncertainty. From a client perspective, too, Seffo et al. (2014), reported that immigrant patients experienced a major problem with language and communication, and that they were therefore compelled to seek help from their children or to 
use an interpreter when they visited healthcare establishments. Since the CCAI-S captures available resources in the organisation, such as interpreters, this enhances the assessment instrument's relevance and potential for implementation.

The CCAI-S needs to be further developed before being implemented in Sweden. Following content validation, more formal statistical procedures are used to assess the validity of a measurement (McDowell, 2006). The next step is to continue the establishment of validity and utility with a larger randomised sample among Swedish occupational therapists. With this in mind, the potential for utilising the CCAI-S can be discussed. The CCAI-S is not limited to be used by only occupational therapists (Suarez-Balcazar, 2011) and this was also confirmed in our study since the results showed that the CCAI-S has the potential to be utilised among other professions as well. Niemeier et al., (2003) emphasise that staff in interdisciplinary rehabilitation team must individualise the handling and care and efforts should be made to recognise behaviours that might lead to poor compliance or seeing services as unhelpful and so it can be avoided. Medical staff should take time to make decisions when working with patients from ethnically diverse backgrounds. Thoughtful and critical thinking should be applied in treatment planning. Hence, the CCAI-S in future may be used in multi professional contexts.

\section{Limitations and future research}

Various aspects of this study need to be taken into consideration. This study is the first one to evaluate an instrument in Swedish for measuring cultural competence in occupational therapists. A focus group methodology (Krueger and Casey, 2015) was chosen so that occupational therapists with a variety of experiences and views could contribute and assist each other in the discussion. The focus groups varied in terms of gender, workplace and the number of years they had been working, which contributed to a diversity of opinions. The variety of participants enhanced the credibility of the study. However, a majority of the participants had a Swedish background and this can be regarded as a limitation. In addition, another shortcoming may be the limited geographic area in Sweden where the participants were working. The small number of participants limits the transferability of the results. Nevertheless, the participants, procedure and data analysis have been described thoroughly in order to facilitate transferability (Graneheim and Lundman, 2004; Krefting, 1991). The study 
involved four to five participants in each focus group. The ideal size of a focus group is between five and eight participants, although four to six have become more common (Krueger and Casey, 2015). The total range of experience is lower in a smaller group (Krueger and Casey, 2015), but the outcome of the discussion depends more on the engagement of the participants in each focus group than on the total number (Dahlin- Ivanoff and Hultberg, 2006). All focus groups were dynamic, and the participants showed commitment. The sampling procedure for inviting occupational therapists by selecting gatekeepers can be considered a limitation, because they may not have been fully aware of all prospective participants or their range of knowledge. On the other hand, the focus groups adhered to the inclusion criteria that participants must have had contact with international clients during the past year.

The first author was moderator for all focus groups, and this ensured that the process used for the groups had a similar structure and content. All participants submitted a written description of what the concept of culture and ethnicity meant, and this, along with the completed instrument, confirmed the statements from transcripts. Dependability was addressed throughout the data analysis by the authors discussing all categories and reaching consensus, and this can be considered a strength (Krefting, 1991).This initial evaluation of the validity and utility of the Swedish version of the CCAI should be regarded as a first step in developing the instrument.

The present study has its point of departure in the increasingly diverse populations in Sweden (SCB, 2016a) and it was considered urgent to develop an assessment instrument for cultural competence. The instrument was developed to capture only ethnicity as one component of diversity. Yet, the authors of the instrument acknowledge that cultural competence encompasses more than that. In addition, the intersection between the different dimensions of diversity, for instance ethnicity and gender, cannot be ignored. Nevertheless, CCAI-S may be a contribution to meet the growing challenges occupational therapists are facing in Sweden today in health care.

\section{Conclusions}


The results from this first study showed that the CCAI-S could be a promising instrument for utilisation in the Swedish context. In order to evaluate the validity and utility of the CCAI-S further, a study will be designed based on the results of the current study but in a larger randomised sample of occupational therapists. This will contribute to continued development of the CCAI-S in the Swedish context. The CCAI-S provides information about practitioners' cultural competence and can be used as a tool for enhancing their level of cultural competence. This may lead to a more effective and client-centered patient care for the increasingly diverse populations in Sweden.

\section{Key findings}

- All items in the CCAI-S were considered valid, although a few were considered to require clarification.

- The CCAI-S was shown to be clinically relevant

\section{What the study has added}

The results demonstrate that the CCAI-S has potential to be utilised in a Swedish context among practitioners. However, further research is needed based on a larger randomised sample.

\section{Acknowledgements}

The authors would like to express their gratitude to the occupational therapists who participated in the study. The authors would also like to thank Professor Yolanda SuarezBalcazar, Department of Occupational Therapy, University of Illinois at Chicago, USA, for her commitment and support throughout the work.

\section{Research ethics}

Ethics approval was not required for this study

\section{Declaration of conflicting interests}


The authors confirm that there is no conflict of interest

\section{Funding}

This research received no specific grant from any funding agency in the public, commercial, or not-for-profit sectors.

\section{Contributorship}

Jane Holstein, Gunilla M Liedberg and Anette Kjellberg contributed to the study design of the study. Jane Holstein, Gunilla M Liedberg and Anette Kjellberg made the data collection. Jane Holstein and Annika Öhman carried out the data analysis. All authors worked with the interpretation of results. The writing of the manuscript was made by Jane Holstein, Gunilla $\mathrm{M}$ Liedberg and Anette Kjellberg. Jane Holstein, Gunilla M Liedberg and Anette Kjellberg reviewed and edited the manuscript and all authors approved the final version of the manuscript.

\section{References}

Aspers P (2011) Etnografiska metoder : att förstå och förklara samtiden. (Ethnographic methods: to understand and explain the present) Malmö: Liber.

Balcazar FE, Suarez-Balcazar Y and Taylor-Ritzler T (2009) Cultural competence: Development of a conceptual framework. Disability and Rehabilitation, 31(14), 1153-1160.

Bearss K, Taylor CA, Aman MG, Whittemore R, Lecavalier L, Miller J and Scahill L (2016) Using qualitative methods to guide scale development for anxiety in youth with autism spectrum disorder. Autism 20(6) 663-672)

Beaton DC, Bombardier C, Guillemin F and Ferraz MB (2000) Guidelines for the Process of Cross-Cultural Adaptation of Self-Report Measures. Spine, 25(24) 3186-3191

Breitmayer BJ, Ayres L and Knafl KA (1993) Triangulation in qualitative research: evaluation of completeness and confirmation purposes. The Journal Of Nursing Scholarship, 25(3), 237-243. 
Connell J, Carlton J, Grundy A, Buck ET, Keetharuth AD, Ricketts T, Barkham M, Robotham D, Rose D and Brazier J (2018) The importance of content and face validity in instrument development: lessons learnt from service users when developing the Recovering Quality of Life measure (ReQoL). Quality of Life Research 27, 1893-1902

Dahlin- Ivanoff S and Hultberg J (2006) Understanding the multiple realities of everyday life: Basic assumptions in focus-group methodology. Scandinavian Journal of Occupational Therapy, 13(2), 125-132.

Darawsheh W, Chard G and Eklund M (2015) The Challenge of Cultural Competency in the Multicultural 21st Century: A Conceptual Model to Guide Occupational Therapy Practice. The Open Journal of Occupational Therapy, 3(2)

Graneheim UH and Lundman B (2004) Qualitative content analysis in nursing research: concepts, procedures and measures to achieve trustworthiness. Nurse Education Today, 24(2), 105-112.

Hjern A (2012) Migration and public health: Health in Sweden: The National Public Health Report 2012. Chapter 13. Scandinavian Journal of Public Health, 40(9), 255-267.

Hultsjö S and Hjelm K (2005) Immigrants in emergency care: Swedish health care staff's experiences. International Nursing Review, 52, 276-285

International Organization of Migration (IOM), (2017). World Migration Report 2018. Available at http://publications.iom.int/ [accessed 12 April 2018]

Krefting L (1991) Rigor in qualitative research: the assessment of trustworthiness. American Journal of Occupational Therapy, 45(3), 214-222.

Krueger RA and Casey MA (2015) Focus groups : a practical guide for applied research. Thousand Oaks, California: Sage Publications.

Liedberg GM, Eddy LL and Burckhardt CS (2012)Validity testing of the quality of life scale, Swedish version: focus group interviews of women with fibromyalgia. Occupational Therapy International, 19(4), 167-175

McDowell I (2006) Measuring health : a guide to rating scales and questionnaires. New York: Oxford University Press. 
Morgan DL (1998) Practical strategies for combining qualitative and quantitative methods: Applications to health research. Qualitative Health Research, 8(3), 362-376.

Niemeier JP, Burnett DM and Whitaker DA (2003) Cultural competence in the multidisciplinary rehabilitation setting: are we falling short of meeting needs? Physical Medicine \& Rehabilitation, 84(8), 1240-1245.

Patton MQ (2015) Qualitative research \& evaluation methods : integrating theory and practice. Thousand Oaks, California: SAGE Publications, Inc.

Polit DF and Beck CT (2004) Nursing research : principles and methods. Philadelphia: Lippincott Williams \& Wilkins.

Polit D F and Beck CT (2008) Nursing research : generating and assessing evidence for nursing practice. Philadelphia: Wolters Kluwer Health/Lippincott Williams \& Wilkins. Polit D F and Beck CT (2016) Nursing research : generating and assessing evidence for nursing practice. Philadelphia: Wolters Kluwer.

Pooremamali P, Persson D and Eklund M (2011) Occupational therapists' experience of working with immigrant clients in mental health care. Scandinavian Journal of Occupational Therapy, 18(2), 109-121.

SCB, Statistiska Centralbyrån (2016a). Befolkningsstatistik. (Statistics Sweden) Available at: http://www.scb.se/hitta-statistik/sverige-i-siffror/manniskorna-i-sverige/in-och-utvandring/ [accessed 12 April 2018]

SCB, Statistiska Centralbyrån (2016b). Från Finland till Afghanistan - invandring och utvandring för födda i olika länder sedan 1970. (Statistics Sweden) Available at: http://www.scb.se/Statistik/_Publikationer/BE0701_2016A01_BR_BE51BR1601.pdf [accessed 12 April 2018]

Seffo N, Krupic F, Grbic K and Fatahi N (2014) From Immigrant to Patient: Experiences of Bosnian Immigrants in the Swedish Healthcare System. Materia Socio-Medica, 26(2), 84-89.

SFS (Swedish Statute Book) 2003:460 Ethical considerations of research involving humans. Availble at https: https://www.riksdagen.se/sv/dokument-lagar/dokument/svenskforfattningssamling/lag-2003460-om-etikprovning-av-forskning-som_sfs-2003-460 In Swedish. [accessed 12 April 2018] 
SFS (Swedish Statute Book) Discrimination Act (2008:567) Available at: https://www.riksdagen.se/sv/dokument-lagar/dokument/svenskforfattningssamling/diskrimineringslag-2008567_sfs-2008-567. In Swedish. [accessed 12 April 2018]

Sim J (1998) Collecting and analysing qualitative data: Issues raised by the focus group. Journal of Advanced Nursing, 28(2), 345-352.

Suarez-Balcazar Y, Taylor-Ritzler T, Portillo N, Rodakowski J, Garcia-Ramirez M and Willis C (2011) Development and Validation ofthe Cultural Competence Assessment Instrument: A Factorial Analysis. Journal of Rehabilitation, 77(1), 4-13.

Suarez-Balcazar Y, Rodawoski J, Balcazar FE, Taylor-Ritzler T, Portillo N, Barwacz D and Willis C (2009) Perceived levels of cultural competence among occupational therapists. American Journal of Occupational Therapy 63(4), 498-505.

Taylor-Ritzler T, Balcazar FE, Dimpfl S, Suarez-Balcazar Y, Willis C and Schiff, R (2008) Cultural competence training with organizations serving people with disabilities from diverse cultural backgrounds. Journal of Vocational Rehabilitation, 29(2), 77-91.

Taylor-Ritzler T, Balcazar FE, Suarez-Balcazar Y, Kilbury R, Alvarado F and James M (2010) Engaging ethnically diverse individuals with disabilities in the Vocational Rehabilitation system: Themes of empowerment and oppression. Journal of Vocational Rehabilitation, 33(1), 3-14.

WMA, World Medical Association (2013) Declaration of Helsinki: ethical principles for medical research involving human subjects. doi:10.1001/jama.2013.281053

Wray E L and Mortenson PA (2011). Cultural competence in occupational therapists working in early intervention therapy programs. Canadian Journal of Occupational Therapy, 78(3), 180-186. 
Table 1. Demographic characteristics of the participants $(n=19)$.

\begin{tabular}{|c|c|}
\hline $\begin{array}{l}\text { Gender } \\
\text { Women } \\
\text { Men }\end{array}$ & $\begin{array}{l}17 \\
2\end{array}$ \\
\hline $\begin{array}{l}\text { Age }^{1} \\
\text { Mean/士SD/Range }\end{array}$ & $38.6 / 9 / 27-55$ \\
\hline $\begin{array}{l}\text { Highest education }{ }^{2} \\
\text { Research level } \\
\text { Master level } \\
\text { Bachelor level }\end{array}$ & $\begin{array}{l}2 \\
4 \\
9 \\
\end{array}$ \\
\hline $\begin{array}{l}\text { Working Years }{ }^{3} \\
>5 \\
6-10- \\
11-15 \\
16-20 \\
21-25- \\
26-30-\end{array}$ & $\begin{array}{l}8 \\
1 \\
3 \\
3 \\
2 \\
1\end{array}$ \\
\hline $\begin{array}{l}\text { Ethnic background } \\
\text { Sweden } \\
\text { Northern Europe } \\
\text { Southern Europe } \\
\text { South America } \\
\end{array}$ & $\begin{array}{l}16 \\
1 \\
1 \\
1 \\
\end{array}$ \\
\hline $\begin{array}{l}\text { Working areas } \\
\text { Children } \\
\text { Adult } \\
\text { Elderly }\end{array}$ & $\begin{array}{l}2 \\
8 \\
9 \\
\end{array}$ \\
\hline
\end{tabular}

Notes: ${ }^{1}$ Missing data regarding age $n=1$.

${ }^{2}$ Missing data regarding highest education $n=4$.

${ }^{3}$ Missing data regarding working years $n=1$. 
Table 2. The items from the instrument with suggested alterations from the participants

\begin{tabular}{|c|c|c|c|}
\hline Domain & Item & $\begin{array}{l}\text { Suggestion for } \\
\text { alteration }\end{array}$ & $\begin{array}{l}\text { Number of focus } \\
\text { group }(n=4)\end{array}$ \\
\hline \multicolumn{4}{|c|}{$\begin{array}{l}\text { Cultural } \\
\text { Awareness }\end{array}$} \\
\hline & $\begin{array}{l}\text { 1. I openly discuss with } \\
\text { others issues I have in } \\
\text { developing multicultural } \\
\text { awareness. }\end{array}$ & None & None \\
\hline & $\begin{array}{l}\text { 2. I learn about different } \\
\text { ethnic cultures through } \\
\text { educational methods } \\
\text { and/or life experiences. }\end{array}$ & None & None \\
\hline & $\begin{array}{l}\text { 3. I examine my own biases } \\
\text { related to ethnicity and } \\
\text { culture that may } \\
\text { influence my behavior as } \\
\text { a service provider. }\end{array}$ & None & None \\
\hline & $\begin{array}{l}\text { 4. I actively strive for an } \\
\text { atmosphere that promotes } \\
\text { risk-taking and self- } \\
\text { exploration. }\end{array}$ & None & None \\
\hline & $\begin{array}{l}\text { 5. I am sensitive to valuing } \\
\text { and respecting } \\
\text { differences between my } \\
\text { cultural background and } \\
\text { my clients' cultural } \\
\text { heritage. }\end{array}$ & None & None \\
\hline & $\begin{array}{l}\text { 6. I feel that I can learn } \\
\text { from my ethnic minority } \\
\text { clients. }\end{array}$ & None & None \\
\hline & $\begin{array}{l}\text { 7. It is difficult for me to } \\
\text { accept that religious } \\
\text { beliefs may influence } \\
\text { how ethnic minorities } \\
\text { respond to illness and } \\
\text { disability. }\end{array}$ & $\begin{array}{l}\text { Exemplify what } \\
\text { religious beliefs means. }\end{array}$ & 3 \\
\hline & $\begin{array}{l}\text { 8. I do not consider the } \\
\text { cultural backgrounds of } \\
\text { my clients when food is } \\
\text { involved. }\end{array}$ & $\begin{array}{l}\text { This item is very } \\
\text { specific. Other areas } \\
\text { could also be of interest, } \\
\text { such as hygiene }\end{array}$ & 3 \\
\hline
\end{tabular}




\begin{tabular}{|c|c|c|c|}
\hline $\begin{array}{l}\text { Organizational } \\
\text { support }\end{array}$ & & & \\
\hline & $\begin{array}{l}\text { 9. Cultural competence is } \\
\text { included in my work } \\
\text { place's mission } \\
\text { statement, policies, and } \\
\text { procedures. }\end{array}$ & None & None \\
\hline & $\begin{array}{l}\text { 10. My workplace does not } \\
\text { support using resources } \\
\text { to promote cultural } \\
\text { competence. }\end{array}$ & None & None \\
\hline & $\begin{array}{l}\text { 11. My organization does not } \\
\text { provide ongoing training } \\
\text { on cultural competence. }\end{array}$ & None & None \\
\hline & $\begin{array}{l}\text { 12. My workplace does not } \\
\text { support my participation } \\
\text { in cultural celebrations of } \\
\text { my clients. }\end{array}$ & $\begin{array}{l}\text { Clarify what } \\
\text { participation in the } \\
\text { cultural celebrations } \\
\text { means. }\end{array}$ & 4 \\
\hline & $\begin{array}{l}\text { 13. At work, pictures, } \\
\text { posters, printed materials, } \\
\text { and toys reflect the } \\
\text { culture and ethnic } \\
\text { backgrounds of ethnic } \\
\text { minority clients. }\end{array}$ & None & None \\
\hline & $\begin{array}{l}\text { 14. I receive feedback from } \\
\text { supervisors on how to } \\
\text { improve my practice } \\
\text { skills with clients from } \\
\text { different ethnic minority } \\
\text { backgrounds. }\end{array}$ & None & None \\
\hline & $\begin{array}{l}\text { 15. The way services are } \\
\text { structured in my setting } \\
\text { makes it difficult to } \\
\text { identify the cultural } \\
\text { values of my clients. }\end{array}$ & $\begin{array}{l}\text { Exemplify what } \\
\text { structure of services } \\
\text { mean }\end{array}$ & 4 \\
\hline & $\begin{array}{l}\text { 16. I have opportunities to } \\
\text { learn culturally } \\
\text { responsive behaviors } \\
\text { from peers. }\end{array}$ & None & None \\
\hline Cultural skills & & & \\
\hline
\end{tabular}




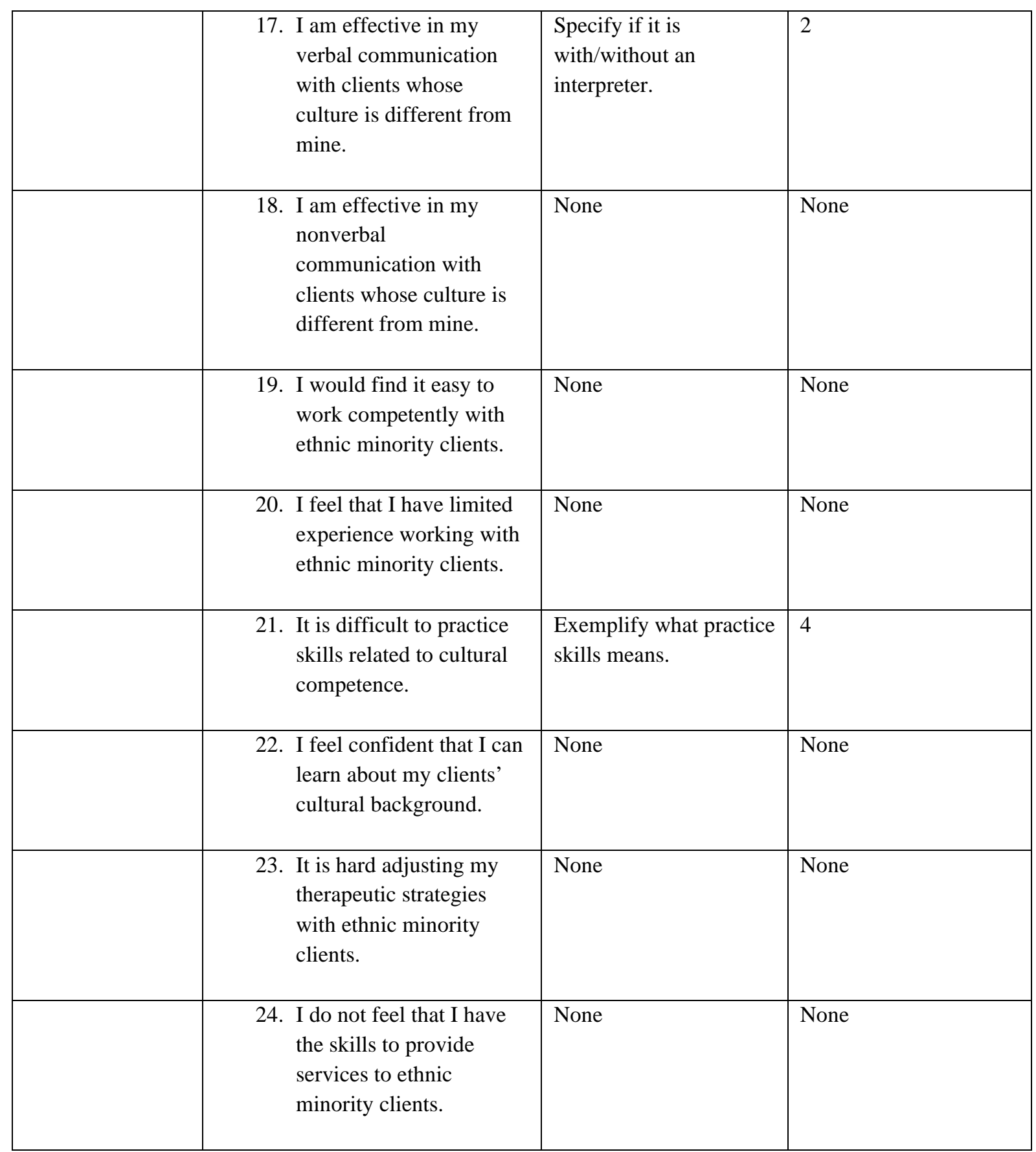

